\title{
INFLUENCE OF INFORMATION TECHNOLOGY ON ORGANIZATION STRATEGY
}

\author{
Mabutho SIBANDA*, Durrel RAMRATHAN** \\ School of Accounting, Economics \& Finance University of KwaZulu-Natal \\ Westville Campus, Durban South Africa \\ *e-mail: sibandam@ukzn.ac.za \\ **e-mail: durrie1988@gmail.com
}

\begin{abstract}
The exponential development of information technology has presented many opportunities to organizations; however, it has also presented several challenges. A key challenge is how do organizations effectively use information technology and incorporate it into their strategies to make full use of its capabilities as an enabler. The fast-changing nature of information technology has resulted in little empirical evidence on how it influences organization strategy. The Strategic Alignment Model was a popular model created to assist organizations to align their information technology and their business strategy; however, the growth of technology may have made this model irrelevant in this age. Therefore, organizations need to determine what factors drive this alignment. Using hermeneutic phenomenology, 12 in-depth interviews were conducted within IBM South Africa to determine real-life drivers that help create this alignment. The themes derived from the interview texts reveal that consumers are becoming more empowered; therefore, organizations need to be more flexible in their business models and strategies. Furthermore, the integration of cross-functional roles in the organization at the management level allow for improved alignment between information technology and strategy as better integrated roles bring a combination of these two elements.
\end{abstract}

Keywords: information technology, strategy, strategic alignment model, business models, digital, market disruption, phenomenology.

\section{Introduction}

Over the past few decades, information technology has seen accelerated growth, which has had a significant impact on how organizations operate and has forced them to rethink how they conceptualize their strategies. Progress for organizations in this "information age" is pivoted on the inclusion of information technology in their overall strategy, a trend that has persisted for the past two decades. This trend was already evident in the early 1990s, when, for example, in General Electric's (GE) 1995 annual report, its CEO named information systems as a top priority in the company's strategic focus. Information technology is seen as a critical enabler to achieve long-term business goals, and it cannot simply be bolted onto existing strategies; rather it needs to be a driver (Dennis and Walsh, 2015). To address this need, the Strategic Alignment Model was developed to enable organizations to make better use of their information technology assets (Luftman, 2015).
However, with the ongoing development in information technology, these models may soon become irrelevant. This presents an issue for management, because ensuring that business and information technology work in unison is a priority. The key reason why this is a concern is because information technology has a direct impact on the business model of the organization. Some obvious examples of the impact of information technology on business include Google, whose dynamic search engine used the growing Internet and need for access to information for the company to create a platform to service its customers (Mangematin and Baden-Fuller, 2015).

\section{Strategic alignment}

There are very few studies addressing information technology and its strategic implementation within the organization (Sahal, 1981; Adner and Levinthal, 2002; Ramrathan and Sibanda, 2015). This lack is largely due to the accelerated growth of information technology, which has shifted away from its traditional orientation of purely providing support to 
a strategic driver. This advancing role that information technology plays within the organization needs to be conceptualized and constructed so that an organization can align itself to take full advantage thereof (Cuenca et al., 2014). The Strategic Alignment Model was developed to conceptualize this alignment. Strategic alignment is built on two foundational blocks, strategic fit and functional integration (Goepp and Avila, 2015). Strategic fit realizes the need for any strategy to target both the internal and external domains (Goepp and Avila, 2015).

As seen in Fig. 1, external domains relate to the business environment in which the organization competes, with a focus on decisions, such as makeversus-buy decisions, and the strategic attributes that sets the organization apart from its competitors (Chou, et al., 2015), whereas the internal domains are focused on the logic of administrative structures, the rationale behind the design or redesign of business processes, and the development of human resources to attain set competencies (Chou, et al., 2015). Regarding the business strategy domain, the fit between external positioning and internal arrangement is critical for maximum gains. The Strate- gic Alignment Model assumes this fit as being relevant for information technology strategy (Cuenca, et al., 2014). Hence, in terms of the external domains, the model proposes that the position of the organization in terms of the information technology marketplace is dictated by three choices. First, technology scope relates to specific technologies that support or shape strategic initiatives, which is comparable to business scope in the business strategy domain (De Haes and Van Grembergen, 2015). Second, systematic competencies are those attributes of information technology strategy that support the creation of improvement of business strategies. This attribute is comparable to business competencies, which are the attributes that set an organization apart from its competitors (Coltman, et al., 2015; De Haes and Van Grember-gen, 2015). Lastly, information technology governance are the drivers used to obtain the required competencies. This attribute is comparable with business governance, which involves making decisions in a Web of organizational relationships (Coltman, et al., 2015; De Haes and Van Grembergen, 2015).

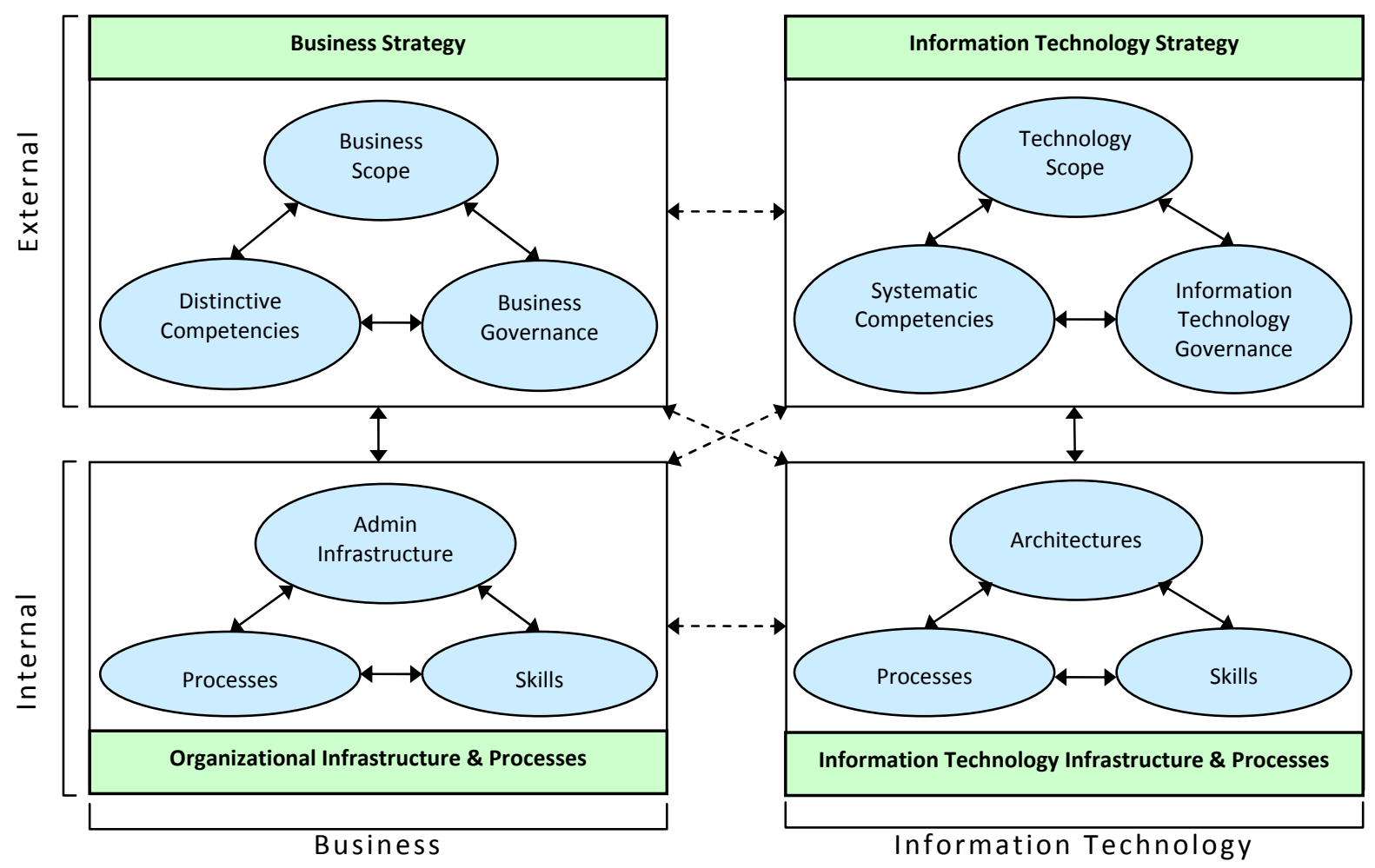

Figure 1. Strategic Alignment Model (source: Coltman, et al., 2015, p.96) 
Similarly, the internal domains must address the following elements. First, information systems architecture defines the hardware, software, communication, data architecture, and applications that form the technical infrastructure (Cuenca, et al., 2014; Coltman, et al., 2015; De Haes and Van Grember-gen, 2015). This attribute is comparable to administrative structure within business strategy.

Second, information systems processes define the processes that are vital to the operations of the information systems infrastructure (Cuenca, et al., 2014; Coltman, et al., 2015; De Haes and Van Grembergen, 2015). This attribute is comparable to designing business processes to carry out business strategies. Lastly, information systems skills refer to hiring, developing, and training to bolster the capabilities of employees' and their ability to be productive within the information technology domain (Cuenca, et al., 2014; Coltman, et al., 2015; De Haes and Van Grembergen, 2015). This attribute is comparable to the skills required to fulfill the desired strategy in the business strategy domain.

Historically, information technology was seen as just the cost of doing business; however, it has emerged as a critical enabler of business transformation that delivers organization-wide advantages (Ramrathan and Sibanda, 2015). Hence, it is of paramount importance that organizations pay close attention to both the external and internal components of information technology strategy and elevate it from its traditional focus to align with business strategy.

Functional integration is the second dimension of the Strategic Alignment Model. This dimension models how business and information technology integrate (Coltman, et al., 2015; Goepp and Avila, 2015).

Fig. 1 illustrates the Strategic Alignment Model with its various interactions. It identifies two types of integration between business and information technology strategies. The first is strategic integration, which is the linkage between information technology strategy and business strategy, highlighting information technology functionality to support business strategy (Coltman, et al., 2015; Goepp and Avila, 2015).
The second is operational integration, which represents the linkage between organizational infrastructure and processes and information systems infrainfrastructure and processes (Coltman, et al., 2015; Goepp and Avila, 2015). These two types are critical as they portray internal coherence and take advantage of the increasing benefits of information technology on the organization.

While the Strategic Alignment Model has been popular, as it was one of very few models developed early on to drive the convergence of business and information technology, it is not without criticism. Preston (2014) suggested that there may be a more robust way to define the level of information technology alignment required. He recommended that the focus should be placed on measurable drivers, such as customer satisfaction or business value, rather than on internal performance indicators as they often lack practicality (Preston, 2014).

In addition, there is concern about how well the model holds up in the face of exponential technology growth. Top management, who are key in terms of the different perspectives of the model, may find it difficult to keep abreast of technological changes, which is true for many organizations as they continue to rely on legacy applications that may be inefficient.

Another flaw highlighted by Luftman (2015) was that the framework of the Strategic Alignment Model did not have much empirical backing. In addition, while the Strategic Alignment Model dealt with the aligning of business and information technology, it did not address the "level" of alignment between the two (Luftman, 2015).

The importance of this alignment is highlighted by a Chief Information Officer (CIO) study conducted by Kappelman, et al. (2014), which placed the alignment of information technology as one of their top three challenges. Therefore, understanding how information technology influences strategy is vital as it can allow organizations to better align and use technology to drive their strategies. 


\section{Methodology}

Owing to the limited amount of empirical evidence surrounding information technology and its influences on organization strategy, an exploratory approach would need to be adopted. For this approach, the most powerful method would be to get insight into how the influence of information technology works in the real world and how it has been experienced by individuals who make the decisions in this regard. Therefore, hermeneutic phenomenology was selected as the methodology of choice. Hermeneutic phenomenology incorporates the philosophies underpinning both phenomenology and hermeneutics (Kafle, 2013). Hermeneutics brings the interpretive element to clarify the meanings in the respondent data (Spence, 2016). Similar to phenomenology, hermeneutic phenomenology is focused on the human experience within the world as it is lived in (Spence, 2016). It is tuned to explicate aspects within experience that an individual may overlook, with the aim of cultivating meaning and establishing a sense of understanding. This methodology provides justice to the human experience through anecdotal narrative, which results in hybrid texts that can even illuminate silences (Laverty, 2003).

Hermeneutic phenomenology is largely based on the interpretation of text, and the approach advocates the creation of a rich, deep account of the phenomenon through textual descriptions (Cohen, et al., 2000;
Kafle, 2013). The use of interviews has been flagged as the primary means for collecting information under this methodology for various reasons (Kakkonen, 2006; Langdridge, 2007; Khan, 2014). First, interviews are used for exploring and collecting stories (narratives) of lived experiences, which allows participants to share their experiences and stories in their own words. Second, it allows for the researcher to establish a conversational relationship with the participant to better understand the experience, which is achieved through reflection on the topic with the participant (Ajjawi and Higgs, 2007).

Furthermore, because this is an exploratory study, semistructured interviews were used as they enable the understanding of variables and relationships that may not have been explicitly defined because of the lack of empirical backing.

\section{$4 \quad$ Interview analysis}

In keeping with best practice within hermeneutic phenomenology, the thematic data analysis method was used within the understanding and guidance of the hermeneutic circle. The hermeneutic circle is the iterative process of understanding and interpretation, which is seen as the movement between the parts (data) and the whole (developing the conceptualization of the phenomenon), each giving meaning to the other (Boell and Cecez-Kecmanovic, 2010). This process is highlighted in Fig. 2.

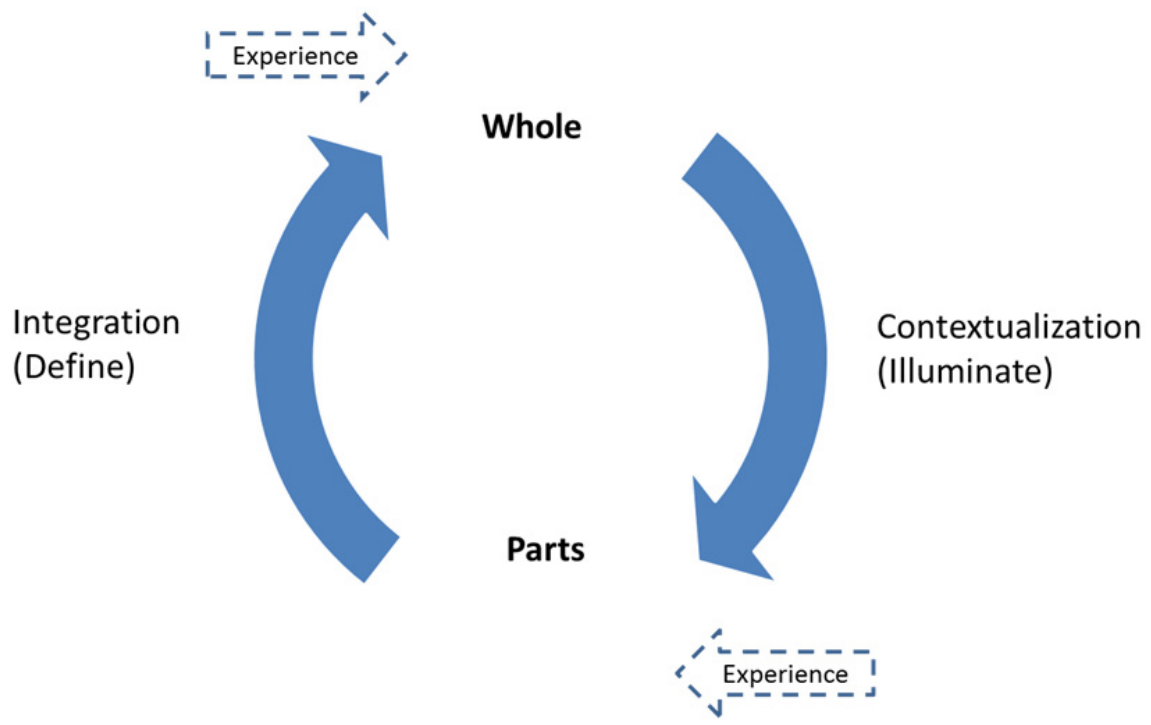

Figure 2. The Hermeneutic Circle (source: Bontekoe, 1996, p.4) 
This process enables the researcher to remain cognizant of questions that may arise from studying the phenomenon and enables the text to "speak." The process of dialogue engaged with the text fosters a sense of understanding. The process of interpretation allows for the act of convergence of insight with regards to the researcher and text (Bontekoe, 1996).

\section{Data}

IBM South Africa was used as the source for participants. A better response rate and access was ensured because the researcher (Durrel Ramrathan) is an employee of IBM, an advantage in the light of the usually poor response rates to surveys from senior management. In addition, that the researcher is a colleague also ensures that participants feel more comfortable and so likely to be more forthcoming with information, which is key to this type of research.

While questions around sample size are persistent within quantitative research, it is somewhat irrele- vant within qualitative research (Kvale, 1994; Englander, 2012, Palinkas, et al., 2015). Questions relating to sample size stem from the misconception that a large sample size is required to be able to generalize the results to the population. However, generalizability need not solely rely on statistics.

If a qualitative study can achieve generalizability and representativeness from a small sample, then it can adhere to scientific criteria as well as a quantitative approach (Kvale, 1994; Englander, 2012; Palinkas, et al., 2015). The phenomenological method recommends a minimum sample of three respondents, with a maximum of 30 participants to be used for this type of study (Trigwell, 2000; Englander, 2012; Stenfors-Hayes, et al., 2013). An additional influence on the sample size for this research is related to the fact that upper levels of management were targeted. Historically, when targeting senior members of an organization, the expected response rate is approximately $40 \%$ (Khatri and $\mathrm{Ng}, 2000$ ). Therefore, a sample of 12 was targeted and distributed as per Table 1 .

Table 1. Sample Distribution

\begin{tabular}{|l|c|c|}
\hline \multicolumn{1}{|c|}{ Management Level } & Criteria & Sample Size \\
\hline Executive Level & $\begin{array}{c}\text { Minimum 10 years of experience } \\
\text { and within executive level role set }\end{array}$ & 4 \\
\hline Senior Level & $\begin{array}{c}\text { Minimum 10 years of experience } \\
\text { and within senior management level role set }\end{array}$ & 6 \\
\hline Middle Level & $\begin{array}{c}\text { Minimum 10 years of experience } \\
\text { and within middle management level role set }\end{array}$ & 2 \\
\hline
\end{tabular}

\section{$6 \quad$ Results}

Interviews were conducted with 12 participants within the guidelines dictated by the research methodology. These 12 participants were split over various management levels. In addition to the management levels, years of experience was also a factor in selection, with only employees who had experience levels of 10 years and upwards are considered. The years of experience for the sample ranged from 10 to 25 years as seen in Table 2. The split assisted in covering the viewpoint of the entire organization.

The face-to-face interviews were in-depth and lasted between 40 and $70 \mathrm{~min}$. All interviews were audio recorded (with permission) and later transcribed word for word. The total number of pages of transcribed interviews came to 94 pages. These transcribed interviews were used to create the themes using the hermeneutic phenomenology method via thematic data analysis within the hermeneutic circle. 
Table 2. Interview Participants

\begin{tabular}{|c|c|c|c|}
\hline Number & Respondent & Management Level & Years of Experience \\
\hline 1 & $\mathrm{~F}$ & Executive & 16 \\
\hline 2 & $\mathrm{G}$ & Executive & 22 \\
\hline 3 & $\mathrm{M}$ & Executive & 22 \\
\hline 4 & $\mathrm{I}$ & Executive & 19 \\
\hline 5 & $\mathrm{P}$ & Senior & 19 \\
\hline 6 & $\mathrm{~W}$ & Senior & 20 \\
\hline 7 & $\mathrm{O}$ & Senior & 16 \\
\hline 8 & $\mathrm{~K}$ & Senior & 25 \\
\hline 9 & $\mathrm{~N}$ & Senior & 17 \\
\hline 10 & $\mathrm{Q}$ & Senior & 17 \\
\hline 11 & $\mathrm{H}$ & Middle & 14 \\
\hline 12 & $\mathrm{~L}$ & Middle & 10 \\
\hline
\end{tabular}

The following themes were developed by analyzing the rich transcribed interview texts using the thematic data analysis within the hermeneutic circle.

- Theme 1

Increasingly empowered consumers are encouraging organizations to move toward more digital and fluid business models.

Consumers are now better informed and have more access to information than ever before. Information technology has enabled multiple digital platforms, which has given organizations unparalleled reach to consumers. This access is driven by the surge in smartphone usage and, in turn, mobile applications and the increasing use of the Internet to complete tasks. For example, consumers do not have to enter a bank to open an account or make transactions, as this can all be done from the comfort of their homes or while on the go using their mobile phones. This mobility is in direct contrast to the traditional methods in which consumers had to physically go into a bank.

Participants in this study believed that digital platforms have created an ecosystem that opens up a number of opportunities and challenges for organizations. There are two main opportunities created for organizations. First, information technology pro- vides organizations with a platform to offer a holistic service to consumers, allowing organizations to converge across industries. For example, Vodafone launched a product called "M-Pesa," which enables users to transfer money to others using their phone without the need to have a bank account (Vogt, 2015). First National Bank (FNB) in South Africa is the largest retailer of Apple devices in the country and has begun offering telecommunications offerings to its customers (Vandermerwe, 2014). These examples highlight how organizations are able to converge across industries and better service their customers.

The second opportunity is that organizations are fast adopting such digital approaches because of the cost reduction they bring. If an organization had to service its customer base using traditional methods, meaning high physical interaction, it would be very costly. Therefore, by going digital, organizations can pass on the work to their customers, so instead of a banking consultant filling and scanning documents to open a new account, the customer does all this work online and just submits the application. Such an approach allows an organization to reduce its costs and become more efficient. Participants agreed that the major challenge this approach presents to established organizations is that it lowers 
barriers to entry, which in turn increases competition.

This increased competition is largely due to the ease of access to information technology and the digitization of supply chains. For example, a company need not necessarily hold any inventory, such as eBay, an online store that links customers looking for goods with customers willing to sell.

Therefore, eBay competes with traditional retailers that need to store and manage inventory, which results in higher costs. Thus, the movement is toward digital business models in reinventing how organizations interact with their customers and how they transfer value. This interaction of the organization with consumers has been conceptualized in Fig. 3, based on this discussion.

Fig. 3 illustrates that strategy informs the business model, which in turn informs the business process. However, unlike traditional flows, the business process is enabled by information technology that creates an ecosystem that encompasses the customer.

While the flow may look simple, executives noted that these flows need to be harmonized and continually reviewed, because information technology evolves so rapidly that an organization cannot afford to be rigid and needs to actively update its business model to reflect the technologies that consumers are engaging in.

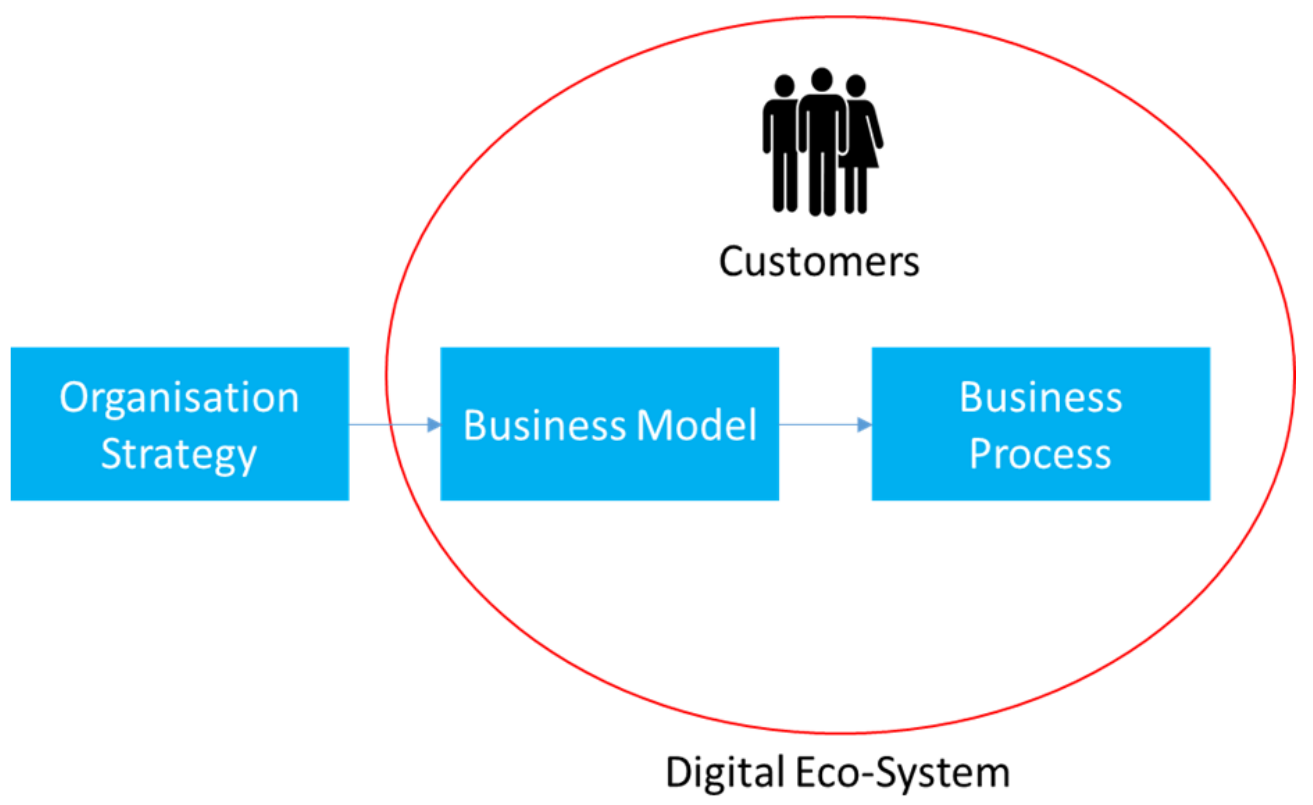

Figure 3. Digital Business Model

"The world is moving towards digital and the world is moving toward giving people a better customer experience. So, people don't need to go and sit for an hour in traffic just to go and experience something... What that means is that you get the benefit as a consumer of being able to in your space, doing what you want to do in terms of researching an item, what it benefits the supplier with, is that you don't have a 100 people that are wasting that salesman's time, so you get the benefits of both sides, there is no doubt." (Respondent F, Paragraph F1.1.20)

\section{- Theme 2}

Market disruption is becoming a fad and organizations need to focus on optimizing their value chain rather than disrupting the market.

Throughout the interviews, participants continually brought up the concept of market disruption. The increased digitization of interactions with consumers has opened markets to innovations that would transform and disrupt how that market operates. A prime example of this is the launch of Uber, which is a paperless mobile taxi hauling application. 
Uber allows consumers to seamlessly order a taxi to their exact location within minutes and they do not need cash on hand to pay, as the service is linked to their credit card (Wallsten, 2015). This application completely disrupted the legacy taxi operations in all regions in which this application was launched.

Market disruption was viewed by Heikkilä et al. (2015) as serving the needs of consumers who were not previously, or not effectively, served by an incumbent in the market. It is this kind of innovation that participants refer to as market disruption (Heikkila et al., 2015). However, participants urge that this model has become a focus for many organizations where they are striving to innovate with the goal of disrupting the market. The thought is that you do not want to disrupt the market, but you want to enable the market so that you can benefit from it. Google is a prime example of this, because Google created a free community with its search engine, email, online storage, and various other products. Therefore, by enabling this community to perform a multitude of tasks via a single platform, they were able to profit from the advertising. While the suggestion is not that organizations follow this model exactly, but that this example illuminates how enabling can lead to success.

In addition, market disruption is primarily driven by start-ups who go through destructive phases of growth and are able to take the risks to innovate. Large organizations are not in such an agile position as they have more to lose and shareholders to report to. Furthermore, disruption can only be fueled by a user need and not just set as a goal to drive towards. In the Uber example, it was driven by the proliferation of smartphones and the need for convenience in an industry that was notoriously bad at customer service.

Lastly, market disruption is only disruptive in monopolistic or oligopolistic markets and cannot be effective in competitive markets. Heikkilä et al. (2015) caution that organizations that simply strive to maintain their competitive position and technological standing will end up in a fallacy where they only serve their current customer base and leave space for other competitors to address the rest of the market. This argument supports the notion that organiza- tions need to better enable the market itself and not just its customer base.

"Disrupt has been used way too much as a word. I think we have to redefine what disruptive technology means, because you do not want to disrupt, you want to support, you want to enable. Disrupting markets and things, the whole of the model that everyone has talked about, it only works in very legislated environments. Environments with lots of barriers that you can quickly break down using digital... It's going to be more enabling technologies that take whole pieces out of the value chain or pieces out of the process" (Respondent W, Paragraph 1.1.26).

- Theme 3

Business and information technology strategy are two sides of the same coin; this intertwining sees information technology become an integral part of overall strategy, which is signified by the creation of multiple cross-functional roles.

The relationship between strategy and information technology was largely discussed with the senior management and executive participants. Executives and senior managers believe that both business strategy and information technology are no longer separated and are closely intertwined. This relationship is because the increasing outreach of information technology has made business an impossible prospect without the incorporation of information technology.

Historically, business strategy and information technology strategy have been separated and siloed in their operations. There have been frameworks such as the Strategic Alignment Model that attempt to lay out how business strategy and information technology strategy communicate and adapt (Goepp and Avila, 2015). However, there is the belief that these models may fast be becoming outdated, as the organization has already begun the shift to a consolidated strategy focus, which does not view information technology as separate.

Taking banking institutions as an example, with the majority of clients making use of and interacting through online banking and mobile banking applications, the widespread availability of the technology that forms the foundation for these platforms are paramount to the banks' strategy. Furthermore, this 
shift is also reflected in the shifting and creating new roles within the organization.

Executive roles such as the Chief Financial Officer (CFO) and Chief Marketing Officer (CMO) were historically business focused, but nowadays these executives are cross-skilled with a large percentage having information technology backgrounds. In addition, large buyers of information technology solutions are CFOs and CMOs, who are striving for efficiency and effectiveness. A recent study conducted found that there has been a significant change in the initiation of information technology projects. Traditionally, it was the CIO who handled all the information-technology-related matters and drove projects; however, now CIOs initiate around 32\% of information technology projects, while other business leaders initiate $31 \%$ of information technology projects (Kart and Heudecker, 2015).

This shift highlights how roles within the organization need to be built around a sound understanding of how technology works and how it needs to work in its business. Furthermore, new roles have been created within the organization that are a cross between business and technical. These include roles such as the Chief Digital Information Officer (CDIO), Chief Analytics Officer (CAO), and Chief Technology Officer (CTO), all of which are a unique blend of business and information technology to better steer strategic initiatives of the organization.

Horlacher and Hess (2016) found that the creation of these new roles within the organization are a direct result of organizations realizing the value of information technology as an enterprise asset that is crucial to defining strategic initiatives for organizations. In addition, these changes at the executive level act as a signal of convergence to filter down through all levels of the organization (Horlacher and Hess, 2016).

While information technology has become a critical driver of strategy, it brings its own challenges. One pertinent one is keeping an agile strategy that keeps up with the constant change in the information technology space. For example, technology in a competitive market results in frequent innovation by competitors, and organizations need to respond and anticipate these moves or they will be left behind as organizations are now competing on technology (Wu and Chiu, 2015).

The scope of information technology has broadened and is a fundamental conduit through which an organization executes its strategy and business models. As a result, it has brought on a digital revolution in how a consumer is interfaced with, because organizations are striving toward electronic records and storage, which results in greater efficiency and a cost saving for them. Participants in the sample have argued that the term "information technology" is going to be rephrased as "digital" as we progress with this movement.

This change is proven by how many organizations are beginning to incorporate this term in their strategies more and more and within the organization itself. For example, IBM has changed the name of its analytics and strategy department to simply "digital," this is in order to reflect the shifting concepts in the marketplace.

"I think in the new era those barriers are going to be broken down or going to have to be broken down. You need CFO's who are conversant in technology and you need CIO's who are conversant in financial matters. Today if a CIO cannot quantify a business case or a benefits case or an IT solution, they don't qualify to be a CIO. In today's terms if Chief Marketing Officer doesn't understand analytics and the power of data, they should not be in that job. In today's terms if the CFO cannot understand the impact of technology in an organisation - in fact in many organisations, people who buy enterprise applications, are CFO's. So, what you find is there is an understanding and the application of technology in organisations has cut across different roles now." (Respondent G, Paragraph G1.1.16)

\section{$7 \quad$ Discussion}

As consumers become more empowered with information, organizations need to ensure that they are adequately positioned to service the needs of these consumers. Key to enabling this is to make sure that they are agile enough to respond to the constantly changing needs of consumers, as well as how they are engaged. 
For example, older generations may prefer a more personal touch while millennials prefer more social interaction via some online platform. To do this, organizations need to ensure that information technology is included in their overall strategy and this needs to be driven from the top. It may require the introduction of new roles such as the CDIO and $\mathrm{CAO}$ to ensure that the business and information technology speak the same language.

Furthermore, this convergence of roles will drive digital business models that are fluid and cost effective to work with and change. These digital models must be able to enhance business processes, such as the banking example discussed earlier, which pushed the workload to customers by digitally enabling them. While implementing only digital models may not be possible for all organizations, it enables them to easily optimize pieces of their value chain without much disruption. And this is what organizations need to be focusing on, optimizing pieces of their value chain rather than aiming for market disruption, which is only possible in certain environments.

One of the key pieces that can be optimized is the information integration across the value chain, from operational information to strategic information. As the information is digital, the flow is smooth and can be easily integrated so that organizations can have insight into what is working and what is not and, thereafter, alter their approach, therefore, making strategies flexible and agile.

\section{Conclusion}

The constant advancement of information technology has major influences on how organizations operate both internally and externally. These influences are further exacerbated by the empowerment technology has given to consumers. Organizations need to be cognizant of how to effectively use information technology to stay relevant and not be outpaced by innovators or market disrupters. Therefore, it is vital that information technology forms part of their strategies and is not just a separate siloed element.

The constant development of information technology makes it difficult to apply empirical models as these quickly become out of date, such as the Strategic Alignment Model. However, the results from the study reveal that organizations need to move to more digital processes and business models, primarily because these allow the organization to be flexible in its strategies and response to market dynamics.

In addition, it is better to enable markets rather than search for ways to disrupt them, as "market disruption" is just a fad. Last, a key measure that organizations can implement to ensure that business and technology align and form two parts of the same coin is to create cross-functional roles.

These roles are a mix of business and technology and require that the people who fill these roles understand both and are, therefore, able to link effectively the two strategies created.

\section{$9 \quad$ References}

[1] Adner, R. and Levinthal, D.A., 2002. The Emergence of Emerging Technologies. California Management Review, 58, pp.50-66.

[2] Ajjawi, R. and Higgs, J., 2007. Using Hermeneutic Phenomenology to Investigate How Experienced Practitioners Learn to Communicate Clinical Reasoning. The qualitative report, 12, pp.612-638.

[3] Boell, S.K. and Cecez-Kecmanovic, D., 2010. Literature Reviews and the Hermeneutic Circle. Australian Academic \& Research Libraries, 41, pp.129-144.

[4] Bontekoe, R., 1996. Dimensions of the Hermeneutic Circle. Atlantic Highlands, N.J, Humanities Press.

[5] Chou, F.K., Wang, E.T. and Yang, F., 2015. Realizing IT Strategic Alignment and Business Performance: An Integration of Three Perspectives. Journal of Information Technology, 30, pp.101-118.

[6] Cohen, L., Manion, L. and Morrison, K., 2000. Research Methods in Education. Teaching in Higher Education, 41, pp.45-67.

[7] Coltman, T.R., Tallon, P.P., Sharma, R. and Queiroz, M., 2015. Strategic IT Alignment: Twenty-five Years on. Journal of Information Technology, 30, pp.91-100.

[8] Cuenca, L., Boza, A., Bas, Á.O. and Trienekens, J.J., 2014. Business-IT Alignment and Service Oriented Architecture-A Proposal of a Service- 
Oriented Strategic Alignment Model. International Conference on Enterprise Information Systems, Porto, Portugal, pp.490-495.

[9] De Haes, S. and Van Grembergen, W., 2015. Enterprise Governance of IT, Alignment and Value. Enterprise Governance of Information Technology. Springer.

[10] Dennis, D. and Walsh, F., 2015. Align Business Strategy with Information Technology. Guidelines of IT Management, 23, pp.1-16.

[11] Englander, M., 2012. The interview: Data Collection in Descriptive Phenomenological Human Scientific Research. Journal of Phenomenological Psychology, 43, pp.13-35.

[12] Goepp, V. and Avila, O., 2015. An ExtendedStrategic Alignment Model for Technical Information System Alignment. International Journal of Computer Integrated Manufacturing, 10, pp.1-16.

[13] Heikkila, J., Heikkila, M. and Bouwman, W., 2015. Business Modelling Agility: Turning Ideas into Business. Bled eConference, Bled, Slovenia. AIS, pp.109-124.

[14] Horlacher, A. and Hess, T., 2016. What Does a Chief Digital Officer Do? Managerial Tasks and Roles of a New C-Level Position in the Context of Digital Transformation. 49th Hawaii International Conference on System Sciences (HICSS), IEEE, pp.5126-5135.

[15] Kafle, N.P., 2013. Hermeneutic Phenomenological Research Method Simplified. Bodhi: An Interdisciplinary Journal, 5, pp.181-200.

[16] Kakkonen, M.-L. 2006. Intuition and Entrepreneurs: A Phenomenological Study of Managerial Intuition of Finnish Family Entrepreneurs. Masters, University of Jyvaskyla.

[17] Kappelman, L., Mclean, E., Johnson, V. and Gerhart, N., 2014. The 2014 SIM IT Key Issues and Trends Study. MIS Quarterly Executive, 13, pp.237-263.

[18] Kart, L. and Heudecker, N., 2015. Survey Analysis: Practical Challenges Mount as Big Data Moves to Mainstream. In: GARTNER (ed.). Stamford: Gartner.

[19] Khan, S.H., 2014. Phenomenography: a Qualitative Research Methodology in Bangladesh.
International Journal on New Trends in Education and their Implication, 5, pp.34-43.

[20] Khatri, N. and Ng, H.A., 2000. The Role of Intuition in Strategic Decision Making. Human relations, 53, pp.57-86.

[21] Kvale, S., 1994. Ten Standard Objections to Qualitative Research Interviews. Journal of Phenomenological Psychology, 25, pp.147-173.

[22] Langdridge, D., 2007. Phenomenological Psychology: Theory, Research and Method. United Kingdom, Pearson Education.

[23] Laverty, S.M., 2003. Hermeneutic Phenomenology and Phenomenology: A Comparison of Historical and Methodological Considerations. International Journal of Qualitative Methods, 2 , pp.21-35.

[24] Luftman, J., 2015. Strategic Alignment Maturity. Handbook on Business Process Management 2. Springer.

[25] Mangematin, V. and Baden-Fuller, C., 2015. Introduction: Business Models and Modelling Business Models. Advances in Strategic Management, 33, pp.11-25.

[26] Palinkas, L.A., Horwitz, S.M., Green, C.A., Wisdom, J.P., Duan, N. and Hoagwood, K., 2015. Purposeful Sampling for Qualitative Data Collection and Analysis in Mixed Method Implementation Research. Administration and Policy in Mental Health and Mental Health Services Research, 42, pp.533-544.

[27] Preston, R., 2014. CIO worries: Security, talent and (sadly) 'alignment'. IT Leadership. Information Week.

[28] Ramrathan, D. and Sibanda, M., 2015. Does Information Technology Spend Impact On Company Performance? Evidence From Accounting And Market-Based Measures. International Business \& Economics Research Journal (IBER), 14, pp.343-354.

[29] Sahal, D., 1981. Alternative Conceptions of Technology. Research Policy, 10, pp.2-24.

[30] Spence, D., 2016. Supervising for Robust Hermeneutic Phenomenology: Reflexive Engagement Within Horizons of Understanding. Qualitative Health Research, 10, pp.971-980. 
[31] Stenfors-Hayes, T., Hult, H. and Dahlgren, M.A., 2013. A Phenomenographic Approach to Research in Medical Education. Medical Education, 47, pp.261-270.

[32] Trigwell, K., 2000. A Phenomenographic Interview on Phenomenography. Journal of Phenomenography, 5, pp.62-82.

[33] Vandermerwe, S., 2014. Gather and Sustain Momentum. Breaking Through. Springer.

[34] Vogt, H., 2015. Making Change: Mobile Pay in Africa. [online] Wall Street Journal. Available: http://www.wsj.com/articles/making-change-mo bile-pay-in-africa-1420156199 [Accessed 03 August 2016].

[35] Wallsten, S., 2015. The Competitive Effects of the Sharing Economy: How is Uber Changing Taxis? New York: Technology Policy Institute.

[36] Wu, L. and Chiu, M.-L., 2015. Organizational Applications of IT Innovation and Firm's Competitive Performance: A Resource-Based View and the Innovation Diffusion Approach. Journal of Engineering and Technology Management, 35, pp.25-44. 